\title{
EXPLORING DOMINANT CHILD PROTECTION DISCOURSES: NEW POSSIBILITES FOR PRACTICE
}

by

Nimo Samater, BSW, York University, 2007

\author{
A Major Research Paper \\ Presented to Ryerson University \\ in partial fulfillment of the requirements for the degree of \\ Master of Social Work \\ in the Program of \\ Social Work
}

Toronto, Ontario, Canada, 2014

(C) Nimo Samater 2014 


\section{AUTHOR'S DECLARATION FOR ELECTRONIC SUBMISSION OF A MRP}

I hereby declare that I am the sole author of this MRP. This is a true copy of the MRP, including any required final revisions.

I authorize Ryerson University to lend this MRP to other institutions or individuals for the purpose of scholarly research.

I further authorize Ryerson University to reproduce this MRP by photocopying or by other means, in total or in part, at the request of other institutions or individuals for the purpose of scholarly research.

I understand that my MRP may be made electronically available to the public. 
Exploring Dominant Child Protection Discourses: New Possibilities for Practice

(C) Nimo Samater 2014

Master of Social Work

Ryerson University

\begin{abstract}
This research study focuses on attachment theory as a dominant discourse in child protection and the experiences of child protection workers. The literature on attachment theory and its influence on Eurocentric/Western knowledge is reviewed. As well, the use of reflective practice in child protection practice is discussed. This study includes qualitative interviews with three child protection workers in Southern Ontario who discuss their practice. Four emerging themes were derived from the narratives of the participants: recognition of attachment theory as being the pinnacle of child protection practice, use of observation as a tool to assess attachment, use of reflective practice and lastly, the stigma of Children's Aid Society and impacts on practice. The findings in this study suggest how practice is led by policies and standards of the child welfare system and is rarely challenged. The need for the child welfare system to validate parent/child beliefs, values and practices from various ethnicities is discussed.
\end{abstract}

Key Words: attachment theory, child protection practice, discourse, narrative inquiry, reflective practice, anti-colonial. 


\section{ACKNOWLEDGEMENTS}

I would like to acknowledge the three participants who have contributed to this study: Penny, Anissa and Madeline. I appreciate the time you have taken to meet with me and sharing your experiences.

A special thank you to my MRP advisor Dr. Susan Silver, for your guidance and support in enhancing my vision for this study.

Lastly, I would like to thank the friends and colleagues I have had the pleasure of meeting and with whom I shared so many great memories. Sophia, Muno, Dio and Gurkiran, thank you for support and sharing many moments of laughter and tears. 


\section{DEDICATION}

I would like to dedicate this research to my parents who continue to be my number one supporters and my rock. I would also like to dedicate this to my family and friends who have been so supportive throughout this academic roller coaster ride and riding it out with me.

Without their continuous support and encouragement, I would not have been able to accomplish all that I have in the last year. 


\section{TABLE OF CONTENTS}

\section{CHAPTER}

Introduction

1

Chapter 1: Literature Review

8

Chapter 2: Theoretical Framework

Chapter 3: Methodology

22

Chapter 4: The Voices

Chapter 5: Analysis

43

Chapter 6: Implications

51

APPENDICES

REFERENCES 
LIST OF APPENDICES

Appendix A - Recruitment email

Page 56

Appendix B - Interview Guide

Page 57

Appendix $\mathrm{C}-$ Consent form

Page 59 


\section{Introduction}

As a child protection worker, I have conducted assessments using attachment theory in order to form decisions, while assessing the attachment and interactions between parents and their children. These experiences have led me to reflect on the significant amount of influence on developmental psychology within child protection services. During my time as a child protection worker, I have observed many families involved with child protection services that varied in cultural and child rearing practices. I began to feel a sense of discomfort when assessing different families using only one dominant attachment theory. Consequently this study gives me an opportunity to step back, to dialogue with other child protection workers, and to formulate ways I might practice within this context of regulated practice with diverse families.

The Ontario child welfare system focuses on improving the safety and well-being of children and youth. Ontario's 46 Children's Aid Societies and Family and Children's Services are the only child welfare agencies mandated by the Ontario Government to protect children from harm (OACAS, 2010). Children's Aid Societies work with other service providers and the community to ensure the safety, well-being and stability of children and youth. As well, Children's Aid Societies' prevent abuse and neglect, improve child safety, maintain children's health and wellness and support and strengthen families to better care for children (OACAS, 2010). Families who come to the attention of CAS are often experiencing poverty, marginalization and exclusion from society, as a result of oppression based on ethnicity, race, gender, class, ability and so forth. A large portion of the families CAS works with are immigrants. In addition, CAS services many different families that are in distress, dealing with addiction issues, have encountered trauma and/or struggling with mental health concerns. In 2011-2012 over 47, 000 families were involved with or served by CAS (OACAS, 2012). 
The field of child protection involves assessing and identifying risk factors impacting a child's mental, emotional and physical well-being. Monitoring, observing and assessing family situations are key elements to making decisions around the best interest of the child, which involves attending and giving evidence in both family and criminal court proceedings. Child protection work also involves investigating allegations that a child may be in need of protection, as well as formulating plans and conducting assessments to ensure the safety and well-being of a child. These practice procedures are conducted in accordance with the Child and Family Services Act from which CAS procedures are derived (Ontario Child Welfare Secretariat, 2006). Child protection also involves apprehending children from their families when the safety of a child cannot be guaranteed. Furthermore, child protection workers are expected to provide crisis intervention, counselling intervention services to families in order to make appropriate referrals in the community, while advocating for and supporting families.

I was a child protection worker for six years and while working as a child protection worker, I often thought about how relevant critical reflection is within child protection practice. It is only since the beginning of my MSW program that I was able to have the space and time to reflect and implicate on my practices as a child protection worker. Therefore, this research study emerged from my reflection on the limitations of applying attachment theory universally across families.

Attachment theory, an essential aspect of developmental psychology has been adopted by child protection workers in order to assess the attachment between parent(s) and child. Attachment theory was developed by empirical researchers such as John Bowlby and Mary Ainsworth, both influenced by the work of Freud and other psychoanalytic thinkers (Bretherton, 1992). Attachment theory suggests that a key developmental task of infancy is forming an 
attachment to the mother or primary caregiver. Bowlby believed that attachment relationship is biologically rooted and functions to promote the infant's survival (Mennen \& O'Keefe, 2005).

In my journey as an anti-oppressive social worker, this research study will explore attachment theory as a dominant child welfare discourse. Dominant discourses are explanations and assumptions that have come to be accepted by the dominant population as the ultimate truth (Lee \& Bhuyan (2013). This study will also examine how the dominant discourse of attachment theory is perpetuated and becomes regulated practices within child protection, as well as looking at how parents and workers are positioned by the discourse of attachment theory. To address these areas, qualitative semi-structured interviews with three child protection workers who have at least two-year work experience were conducted.

An anti-colonial framework will be used in this study since this framework invokes a historical analysis of power relations and the colonial practices that are reproduced by these power relationships. According to George Dei (2012), the anti-colonial discursive framework "involves a theorization of colonial and re-colonial relations and the aftermath and the implications of power and imperial structures on the processes of knowledge production, interrogation, validation and dissemination" (p. 112). Attachment theory reflects Western knowledge that tends to excludes and marginalizes racialized families by using this dominance lens to judge and assess parenting (Smith, 1999). The Western lens is a universal way of mapping or imposing Western ideas and values on all families. As a result, attachment theory is positioned and operates as the dominant discourse in child protection.

The primary objective is to reveal the degree to which attachment theory shapes child welfare practice. By interviewing three child protection workers this study captures how 
attachment theory informs their practice, their relationship with families and relationship with their supervisor.

\section{History of Attachment Theory}

Our first understanding about attachment theory began in the early 1950's with John Bowlby and James Robertson who specialized in the theories of separation. Robertson and Bowlby reached an important milestone by identifying three phases in children's reactions following separation from the mother, which they labelled protest, despair, and detachment (Kobak, 1999). Therefore, the study of children's separation from their parents has been essential to the study of the operation of the attachment processes and practices to the present day. Bowlby and Robertson observed that children experienced the separations as a fundamental threat to their well-being (Kobak, 1999). Additionally, John Bowlby was influenced by the work of Freud and other psychoanalytic thinkers who believed the infant's relationship with the mother developed because she fed them and that the pleasurable satisfaction of the hunger became associated with the mother's presence in positive ways (Bretherton, 1992), which was part of attachment.

Standard practices in the 1950's and 1960's included nannies providing most of the caretaking for wealthy babies, who rarely saw their parents. Poor babies were routinely removed from their mothers to be fed and housed institutionally and later returned to their mothers if the mothers were able to provide for them. Babies and young children who required hospitalization, however lengthy, were limited to standard visiting hours with their parents (normally 1 hour weekly). These were standard practices in North America and there was no awareness they might be harmful (Rutter \& O'Connor, 1999) to a child's development and relationships. 
Mary Ainsworth was a developmental psychologist who began working with Bowlby as a researcher, and made a significant contribution to the development of attachment theory. Her extensive studies laid the groundwork for her later contributions and Bowlby's later formulations (Bretherton, 1992). In the 1960's, Ainsworth devised the procedure called the "strange situation" in order to observe attachment relationships between parent caregivers and their children. She created an assessment tool (the "strange situation") that is still used to study individual differences in attachment quality. She conceptualized the term "secure base", which is key to attachment theory. This refers to an infant's use of an attachment figure as "a secure base from which to explore" or a "haven of safety" (Ainsworth, 1963, p. 89).

Ainsworth studied individual differences in the quality of attachment relationships by studying the organization of this attachment related behaviour. She documented the interplay of the attachment, fear, and behavioural systems that Bowlby (1959) had incorporated into his theory from ethology. She divided these individual differences she found into two categories initially: 1) "secure" and 2) "anxious" or "insecure" (Ainsworth, 1972). The distinct response patterns that emerged in the infants when they were separated from their mothers in the "strange situation" grew to become three categories: 1) "secure," 2) "avoidant," and 3) "ambivalent" or "resistant." The terms described the infant's apparent perception of the caregiver's availability for comfort or protection and the organization of the infant's responses to the caregiver in light of that perception (Weinfeld et al., 1999). These patterns suggested that infants entered the situation with expectations of how their parents would respond to them based on prior experience with them. The infant's expectation of how the mother should respond is what Bowlby called an "internal working model." This concept allows individuals to anticipate the future and make plans. A child relies on the model to decide what behaviour to use in specific situations with 
specific people. Evidence suggests that very young children use representations to predict the future (Heller \& Bemdt, 1981). For example, "secure" attachment occurs when a child has a mental representation that their caregiver is available and responsive when needed; "insecure" attachment occurs when they lack this representation.

Based on Ainsworth's categories and assessment tool (the Strange Situation), securely attached infants are trusting of their caregiver to meet their needs when in distress. Securely attached infants are also able to approach their caregiver directly and positively (Howe et al., 1999). Infants with anxious or ambivalent attachment are often anxious, angry, vigilant, clingy, and preoccupied with the caregiver in a way that disrupts their exploratory behaviour(Weinfeld, Sroufe, Egeland \& Carlson, 1999). They express anger openly, objecting to separation. They refuse to be quickly comforted when reunited with the attachment figure and may express anger in a variety of ways such as continuing to cry for a long period of time and not wanting to be comforted. In this case the caregiver may have been inconsistently responsive and available to the infant. The caregiver's behaviour may have been intrusive at times or over-stimulating and the infant reacts to these behaviours (Weinfeld et al., 1999).

Moreover Weinfeld et al., 1999 also report that infants with avoidant style attachment behaviours are usually not distressed by separation, do not greet warmly on reunion and tend to avoid contact with their caregivers. They are compulsively self-reliant and rarely cry or seek comfort. They express anger indirectly by actively ignoring their caregivers. Caregivers tend to be insensitive to their infants' cues and to dislike close physical contact with the infant (Weinfeld et al., 1999).

An infant with disorganized or disoriented attachment tends to have incomplete or interrupted movement, freezing or stilling behaviour patterns. Rather than feeling safe with the 
parent, the infant is fearful of the parent and experiences confusion and disorientation. Thus, the infant lacks a logical attachment strategy. This pattern is thought to be the direct effect of frightening behaviour or trauma, or the second-generation effect of frightened caregivers' own unresolved trauma or loss (Wilkins, 2012). 


\section{Chapter 1: Literature Review}

This chapter will review research studies on attachment theory and the different paradigms used in these studies, such as positivism and critical paradigms. This will aid in understanding the dominance of attachment theory and the knowledge created about attachment theory. This chapter will also include the application of attachment theory and the dialogue around the universality of attachment theory. Lastly I will conclude with the importance of critical thinking in child protection practice.

\section{Research Studies on Attachment Theory}

Bowlby's attachment theory gained empirical support consistently over time (Ainsworth et al., 1978; DeWolff \& van Ijzendoom, 1997). For example, attachment theory has served as an ideological basis for therapeutic interventions and parent intervention programs that has dominated Western science (Necoway et al, 2007; Rothbaum et al, 2000). Attachment theory has become a global phenomenon; its philosophies continue to be utilized and influenced by researchers, psychologists and social workers.

A large proportion of the literature on attachment theory, as will be desribed below, are empirical studies that included testing hypotheses, gathering quantitative data and observational studies. From an epistemological perspective, the majority of the empirical studies conducted tested hypotheses and gathering quantitative data, which suggests that a positivist (quantitative method) paradigm was used in these research studies. These types of data tend to focus on the outcomes of the study rather than the process. A positivist approach is defined as:

One of the dominant paradigms in social work and the social sciences this century has been positivism. In this paradigm, knowledge is thought to grow out of careful observation and experimentation...the goal of this approach is prediction, so that control over our environment can be achieved. (Fay in Peile \& McCouat, 1997 p. 344) 
Positivist research studies advise that the secure base function of attachment theory is universal across cultures (van Ijzendoom \& Sagi-Schwartz, as cited in Erdman \& Ng, 2010). The concept secure base function is based on the notion that all infants utilize attachment behaviours such as seeking their parent's attention by crying and that parents respond by soothing the infant. Accordingly, infants are able to get comforted, which indicates that they are secure and "that the attachment system functions effectively across cultures" (Erdman \& Ng, 2010, p. 152). An example of how attachment theory can be universally applied is demonstrated through the provisions of the Ontario child welfare system, where attachment theory is used across cultures and families in child protection practice. Furthermore, the majority of studies that confirm attachment theory as a universal and transformative concept, utilize experimental quantitative research methods (Belsky et al, 1984; Carlson, 1998; Durrett et al, 1984; Grossmann et al, 1985; Kermoian \& Leiderman 1986; Tomlinson et al, 2005; True et al, 2001). Neuman (2006) states that "experimental research builds on the principles of a positivist approach more directly than do the other research techniques... and widely used in psychology" (p. 169). This method involves " modifying something in a situation, then comparing an outcome to what existed without the modification" (Neuman, 2006, p. 170). These studies included different communities from various ethnic groups around the world, where a positivist/quantitative method was utilized to conduct the research and cultural differences were minimized and seen as insignificant (Jin, K. M. et al. as cited in Erdman \& Ng, 2010).

Although numerous positivist empirical studies support attachment theory as being a universal concept, researchers have also acknowledged the minimization of cultural variations. For instance, Sümer \& Kağitçibaşi (as cited in Erdman \& Ng, 2010) indicate that "our results further show that beyond parental attachment anxiety and avoidance, the impact of parenting 
behaviours on attachment security should also be evaluated considering the cultural relevance of these behaviors" (p. 173). As well, True et al. (2001) point out that cultural, historical and geographical differences between Western and non-Western infants and their behaviours reflect their experiences. As a result, these researchers have made recommendations to incorporate nonWestern views of attachment in future studies. It is also important to acknowledge local/indigenous perspectives and methodologies when considering attachment practices (Sinclair, 2004).

As well, other researchers do not support the idea of attachment theory as a universal concept across cultures and highlight how different care-giving patterns are designed to foster dependence rather than fostering autonomy and exploration (Rothbaum, 2000). According to a Japanese longitudinal study that examined the universality of some key assumptions underlying use of the "Strange Situation", the researcher concluded that Japanese infants' stress level were beyond the mild level in comparison to American infants and their vulnerability to stress can be attributed to Japanese culture (Takahashi, 1990). In this study, Japanese parents reported never leaving their children alone. Thus, "in Japanese culture it maybe plausible that the extent of the strangeness of the 'Strange Situation' and the accompanying stress go beyond the bounds of 'mild"' (Takahashi, 1990, p. 28). As well, some of the Japanese infants that were identified as being securely attached to their mother in the procedure were too disturbed to be pleased at the time of reunion and instead refused any of their mother's efforts to soothe them (Takahashi, 1990). According to Ainsworth's assessment tool and categories, Japanese mothers would be seen as caregivers that are inconsistently responsive, intrusive and over-stimulating their child, from a child protection standpoint. This study is an example of how attachment theory cannot be applied universally. 
On the other hand, a critical paradigm recognizes dominant ideas that inform research, as opposed to the positivist paradigm. The critical paradigm involves a "critical process of inquiry that goes beyond surface illusions to uncover the real structures in the material world in order to help people change conditions and build a better world for themselves" (Neuman, 2006, p. 95). Heidi Keller has conducted research on attachment theory using a critical paradigm method and she concludes that "there is considerable evidence that attachment theory and research is based on the Western middle-class conception of development with the primary goal of individual psychological autonomy" (Keller, 2013, p. 187). Similarly, Keller, Voelker \& Yovsi, (2005) focused on the different types of attachment practices that exist and concluded that attachment theory is not a universal concept. Peile \& McCouat (1997) recognize the importance of including and understanding the various voices that exist while being critical of the dominant voices that are represented in research. Clearly, Keller et al. (2005) and Keller (2013) were able to demonstrate this in their research studies mentioned above. Furthermore, other studies draw attention to cross-cultural meanings of good parenting insights to ethnotheories about the early stages of life and attachment (Keller et al., 2005; Neckoway, Brownlee \& Castellan, 2007; Rothbaum, 2000). These research studies tend to focus on exploring cultural differences that exist with regards to attachment practices where one community represents an independent culture and the other community represents an interdependent culture. Thus, cross-cultural research involves shifting from a unified theory (attachment theory), in order to foster a better understanding of what is culturally specific about human attachment and move towards indigenous theories of human relationships (Rothbaum et al, 2000; Keller et al, 2005; Neckoway et al, 2007). Conducting research from this perspective brings awareness to the various ways parents from around world engage in and think about 
close relationships. As a result, a better understanding of the different conceptions of attachment emerge and helps clarify that bonds and relationships in other cultures are not inferior rather are adaptations to different circumstances (Keller et al, 2005; Neckoway et al, 2007; Rothbaum et al, 2000).

Furthermore, in positivist research studies observation is often used, which is similar to child protection practice and can be seen as a form of surveillance.

Surveillance is in and of itself a concept of power. For the observer, sight confers power, whereas for the observed, visibility is powerlessness. Surveillance derives its power from the gaze, which immobilizes its subject and normalizes it. (Mungwini, 2012, p.346)

In child protection, surveillance becomes observation. As a child protection worker, I have observed interactions between child and parent(s), in a room (whether in their home or at the office behind a two mirror or in face-to-face situations) with regards to assessing attachment and risk. This demonstrates the power imbalances that exist in both research [between participant(s) and researcher(s)] and child protection practice (between the worker and service user), where the researcher and the worker are positioned as the "expert". As stated by Potts and Brown (2005), "in positivism, the researcher is the expert and is seen as the primary, and often only, person with the power and ability to create knowledge, to act on that knowledge, and to profit from its 'creation'” (p.262). As well, numerous positivist research studies conducted in Japan, Kenya, Cameroon, Germany, United States and Uganda, have impacted on what "normal" attachment should look like (Ainsworth, 1967; Jin, K. M. et al. as cited in Erdman \& Ng, 2010; Durrett et al, 1984; Kermoian \& Leiderman 1986; Carlson, 1998; Tomlinson et al, 2005; Grossmann et al, 1985; Belsky et al, 1984; True et al, 2001). Thus, researchers should be mindful of the communities they are working with and how well they are being represented because 
"representation has consequences and how people are represented is how they are treated" (Madison, 2005, p. 4).

Moreover, attachment theory has profoundly impacted childcare policies for many years in Ontario. Sensitivity and responsiveness is emphasized in day care, residential, and family settings. It is generally accepted that children's early social experiences alter their psychological development and that they need individual care and continuity in their relationships. There is concern about the need to be aware of attachment concerns in clinical and policy development processes and practices. As well, there continues to be a need for a strong correlation between attachment theory and childcare policies (Howe, Brandon, Hinings \& Schofield, 1999; Neckoway et al., 2007; Sinclair, 2004).

It is evident that attachment theory is a dominant discourse in Western society and had been adopted by the Ontario child welfare system. As a result, child welfare polices embedded in everyday processes and procedures tend to normalize Eurocentric values and beliefs and lead to oppressive outcomes such as blaming the individual parents (Sinclair, 2004; Taylor, 2004). Additionally, in my experience as a child protection worker I was trained to use attachment theory, which reinforces dominant discourses about attachment practices and go unchallenged. Strega (2007) discusses the notion of child protection practice focusing on individual responsibility and pathology, as a result of "child welfare's occupational culture and discourse"” (p. 68). Accordingly, non-Western attachment practices suggest that parents are to blame since they are unable to meet the safety and other needs of their children. 


\section{Critical Thinking and Child Protection}

When utilizing critical thinking it is important to be aware of the discursive nature of knowledge production, particularly in regard to attachment theory. According to Strega (2005), "knowledge is not 'discovered' but is a product of discourse and power relations, a discursive struggle over which dominant perspectives or understanding emerges as the one that "counts", the one that has the power to organize relations" (Strega, 2005, p. 218). For example, knowledge produced about attachment and attachment theory is from a Eurocentric perspective, which has shaped our understanding about attachment and has been accepted as "true" knowledge. The work of Bowbly and Ainsworth on attachment theory heavily influences social work practice and child protection, where attachment theory is a standard to conducting assessments. Consequently, we continue to perpetuate these ideologies in our practice and education, lacking critical reflection in practice.

Reflective practice in social work has been associated with attempts by practitioners to distance themselves from their experiences and thereby achieve a more critical view of their practice (Kondrat in D’Cruz et al., 2007). According to Rossiter (2005),

...when we reflect on what is left out of the discursive construction of our practice, we are 'stepping back' from our immersion in such discourses as 'reality' in order to examine whether our practice is being shaped in ways that contradict or constrain our commitments to social justice. This distance from the immediate thought of practice is enabled by a focus on discursive boundaries, rather than technical implementation of practice theories that are part of discursive fields. (p. 5)

The use of critical reflection in child protection practice could bring awareness and attention to the knowledge and dominant discourses that are regulating in child welfare institutions. This will allow for an opportunity to be critical in practice.

As well, in order to resist mainstream epistemology, we must start to think differently about our research and recognize how the process is just as important as the outcome (Potts \& 
Brown, 2005). It is important to "recognize that knowledge is socially constructed and that knowledge does not exist 'out there' but embedded in people and the power relations between us" (Potts \& Brown, 2005, p. 261). Researchers must also be critical of the knowledge that exists in order to understand how it was constructed, who benefited and who did not benefit as well as the impacts on society (Potts \& Brown, 2005). By deconstructing and challenging dominant discourses of attachment theory, the researcher is decolonizing existing knowledge, which introduces different ways of understanding and producing knowledge, such as using narrative inquiry within an anti-colonial framework. 


\section{Chapter 2:Theoretical Framework}

\section{Anti-colonialism}

This chapter will focus on both the anti-colonial approach utilized as the theoretical framework in this study and on the importance of reflective practice, in order to minimize the reproduction of dominant discourses. The anti-colonial perspective is used to deconstruct dominant discourses and to engage in political struggles against the principles and practice of colonization (Hart, 2009). This approach interrogates institutional power, privileges and rationales used to justify and reproduce colonial practices. An anti-colonial framework can help us to resist and challenge the constant subordination of "other" lived experiences and reinforce their position as valued and effectively relevant forms of knowledge. Additionally, an anticolonialism can be defined as "the political struggle and active resistance of colonized peoples against the ideology and practice of colonialism and emphasizes decolonization and affirming Indigenous knowledge and culture" (Pon, Gosine \& Phillips, 2011, p. 400). Also Dei \& Kempf (2006) state that anti-colonialism refers to colonial relations and how these relations and power dynamics are reproduced and the effects on marginalized and colonized populations. This approach dismantles these unbalanced power relations and their effects on colonized populations.

In order to work from an anti-colonial perspective, it is important to recognize the invisibility and fluidity of dominance, called "whiteness", and how it manifests itself to manipulate the power, in order to maintain the status quo throughout society. Lee \& Bhuyan (2013) discuss how “academic studies of whiteness emerged as a way to theorize the racialization of white people; whiteness is a standpoint that promotes Eurocentric ways of thinking, allowing the relational production of norms to remain unrecognized and invisible" 
(p.100). Therefore, decolonizing requires questioning and breaking the ways in which the human condition is shaped by dominant Eurocentric epistemologies. Furthermore, Saraceno (as cited in Lee \& Bhuyan, 2013) indicates that "helping professions in Canada are embedded in a Western world view founded in the privileging of capitalism, heteronormativity, patriarchy, and whiteness" (p. 102). As a result, Western/Eurocentric knowledge such as the practices of attachment theory, reproduce and reinforce these historical colonial relations, imposing child protection workers to utilize this knowledge based on the worker client relationship.

The dominant assumption is that Western/Eurocentric knowledge is universal and applicable to all families. This universally applied theory is imposed on mothers, who are compelled to perform this Western understanding of attachment and parenting. Moreover, Rossiter (2005) discusses the notion of contradiction for child protection workers, where there are "professional expectations to deploy Eurocentric knowledge (attachment theory) while also being positioned to deliver service to those who are an exception to that knowledge" (p.6). Furthermore, Blackstock (as cited in Lee \& Bhuyan, 2014), state that "Western ontology stems from histories of colonization, capitalism and global neo-liberalism, which contribute to ineffective social work interventions" (p. 102). Thus, the power and privilege of whiteness becomes the "center of the societal universe" (Yee \& Dumbrill, 2003, p. 103) where it can uphold its capitalist, neo-liberal interests. Consequently, indigenous ways of knowing have been overshadowed by colonization (Sinclair, 2004). According to Quijano (2000) “... it was precisely such epistemic suppression that gave origin to the category 'Orient' $\ldots$. in different ways in each case, they forced the colonized to learn the dominant culture in any way that would be useful to the reproduction of domination..." (p. 541). 
Colonial influences exist in social work practice and education, which frame the practice of assessing attachment from a Eurocentric perspective, regardless of the culture of the family being considered Sinclair, 2004). Situations such as the "60s scoop" and the idea of "rescuing" children from their mother have occurred due to the policies and practices of the Canadian child welfare system (Sinclair, 2004). This reinforces and reproduces dominant relations of power where attachment theory is emphasized in psychology and social work education and practice (Sinclair, 2004; Taylor, 2004). Therefore, anti-colonialism helps to invoke an historical analysis that shape people's experiences and how certain groups are represented (Baskin, 2003). Moreover, involving the voices, experiences, practices and knowledge of child protection workers who are constantly interacting and working with families from racially diverse backgrounds would assist in getting a better understanding of the power and the impacts of attachment theory within child protection. Dominant discourses go unchallenged as it is assumed that there is general acceptance, and ultimately these concepts become normative. This uncritical acceptance then becomes culturally embedded and transmitted across generations and thus becoming a hegemonic discourse (Das Gupta, 1996).

In social service organizations, the dominant culture may establish itself in a position of power and control, through the privileged social location of whiteness, where Western/Eurocentric knowledge is imposed in child protection practice. Susan Strega (2007) discuses the idea of how theory informs child protection practice. Ultimately, the focus becomes individual responsibility and shifting the focus away from systemic barriers (Taylor, 2004; Sinclair 2004) where parents are being blamed for their parenting styles. Taylor (2004) indicates that social work practice is dependent on child development theory, which has been standardized 
in child protection practice. Child welfare polices and standards are created using white Eurocentric norms (Strega, 2009).

The impact of such norms informing institutional practices such as child protection has had harmful effects on marginalized communities and has resulted in the overrepresentation of marginalized families within the Ontario child welfare system. Child welfare focusing on mainstream values and whiteness, as normative reference points continue to position the role of the expert in the lives of families. Those who depart from the norm are more likely to be interpreted as a risk and as the "other". As families often do not have the power to alter the constructions made about them, they also do not have control over the intrusive responses by child welfare polices and institutions since they are appointed with legal authority. From an anticolonial approach, this questions the institutional power and privilege of Children's Aid Society and the rationale for dominance, including negative unfavourable and essentialist constructs of parents (Hart, 2009). Therefore, workers reproducing and practicing these dominant ideas come from regulated practices that are in place, which have a significant impact on the workers' ability to being critical and challenging standard practices.

\section{Reflective Practice}

Accordingly, reflection is limited to the knowledge being used in practice, which is positioned as the "truth". Social workers and individuals working in professional disciplines have an inherent power based on their role as "professionals", "experts" and "helpers". They have the ability to reproduce dominant and destructive power relations in their interactions with people and systems (Heron, 2005). As well, assessments are influenced by the workers' subjectivities and biases, which are informed by their values, beliefs, level of consciousness and 
social location (Heron, 2005). Therefore, there is a significant amount of power and responsibility in the formulation of assessments. According to Taylor (2006) reflective practice involves the idea of "creating knowledge about practice through experience rather than simply applying ready-made knowledge to practice" (p.192) As well, she emphasizes the need for social workers to operate from "a reflexive approach to their knowledge in order to achieve a critical awareness of their own processes and products" (Taylor, 2006, p. 192). This idea of reflecting on practice is referred to as "reflection-on-action" and "reflection-in-action", which is engaging in the process of practice and afterwards (Taylor, 2006, p.192). Taylor (2006) suggests that reflection on action allows for a better understanding of a practitioner's practice, their "theories" of action and the values they adopt. This demonstrates professional competency within a worker's identity (Taylor, 2005).

Therefore, it is not enough to just acknowledge social location and make known the different aspects of identity because this does not "lead to an interrogation of power relations" (Heron, 2005, p. 343). It is important for social workers to implicate themselves and reflect critically since "critical self awareness ensures that social workers maximize their contributions to decolonization and minimize their implications in reproducing colonialism through their practices" (Pon et al. 2011, p. 401). Barbara Heron (2005) argues that "resisting the reproduction of dominant power relations rests on an analysis of one's subjectivity and subject position" (p. 341). Thus, critical reflection is important to social work practice in order to understand how issues of power and dominance play out in helping professions such as child welfare practice. Rossiter (2005) indicates that "discourses are structured through power relations so that the identification of what is outside prevailing stories may give us a better picture of how power operates" (p. 6). Thus, focusing on the discourse of attachment theory 
allows social workers to become more aware of their own power and its impact on practice with children and families (Collings \& Davies, 2008).

In summary, an anti-colonial approach introduces the awareness of power relations and oppression, giving the opportunity to reflect on practice and knowledge. Since attachment theory is positioned as a dominant discourse in child protection practice, an anti-colonial approach provides the theoretical perspective on how colonial relations are reproduced when using a universally applied theory. The importance of reflective practice is also discussed in this study, in order to explore the use of reflective practice and the cultural, historical and social contexts of child protection workers, as well as the experiences and knowledge that informs their practice. 


\section{Chapter 3: Methodology}

This chapter will focus on the research design used in this study. This research was influenced by an exploratory narrative inquiry method. Hence, this study will explore how parents and child protection workers are positioned in the discourse of attachment theory. In addition, this study will explore the use of reflective practice in child protection, while assessing child welfare concerns and crisis family situations. Through in-depth narrative interviews, this study hopes to give the participants an opportunity to discuss the tensions, challenges and influences in their practice, allowing participants to reflect on their practice further. Interviews with child protection workers will allow us to understand how they engage with issues of attachment theory, how useful they find the theory, other theoretical perspectives they may incorporate into their practice. Additionally, this will aid in how the participants apply attachment theory in their practice and how they understand reflection in practice.

Narrative inquiry is understood as "an interdisciplinary study of the activities involved in generating and analyzing stories of life experiences and reporting that kind of research" (Schwandt, 2007, p. 204). Narrative inquiry also illustrates how people relate to themselves and to their environments (Connelly \& Clandinin, 1990). Additionally, Fook (2002) suggests that, the value of a particular idea or concept (such as attachment theory) does not exist within the concept itself, but in how the concept is expressed or enacted within a particular context or situation. Thus, focusing on child protection workers and their narratives based on their practice experiences, is a viable way to explore attachment theory as a dominant discourse in child protection practice. Given the small fraction of narrative methods in attachment studies, an 
exploratory narrative methodology was seen as an appropriate way of approaching this inquiry. Generally, attachment studies tend to employ positivist experimental quantitative methods. On the other hand, personal story telling has also become a creditable source of knowledge production (Fraser, 2004). The emphasis on storytelling is important in this study as it allows for the participants to frame their own life experiences and assign meanings to them. Chase (2003) discusses the value of narratives and indicates that:

When we listen carefully to the stories people tell, we learn how people as individuals and as groups make sense of their experiences and construct meanings and selves. We also learn about the complexities and subtleties of the social worlds they inhabit. We gain deeper understandings of the social resources (cultural, ideological, historical, and so forth) that they draw on, resist, and transform as they tell their stories. (p. 80-81)

By using narrative inquiry, this study will reveal participants' experiences and their own way of engaging with attachment theory in their practice. This study recognizes that the terms participants use to describe particular experiences and concepts may differ between participants and considers what Squire (2008) describes as uncertain, changeable or variable accounts of experience. These personal stories will be used in order to describe major aspects of the participants and their practice, especially as they relate to attachment theory. A thematic approach was used in this study that explores emerging narrative themes, patterns, similarities and differences between participant experiences (Connelly \& Clandinin, 2000), in order to bring these factors together for useful dialogue.

In conclusion, narratives are powerful tools to contest dominant social practices. According to Chase (2003), learning to hear how the social world is embedded in individuals' stories would require a strong understanding of the concept of cultural ideologies and discourses, as well as the ability to hear how individuals constantly use, make sense of, resist, or transform those cultural resources and constraints. 


\section{Participants}

Participants were selected based on their employment and number of work experience as a child protection worker, who formulate assessments with regards to family situations. Due to the time constraints of the study, only three child protection workers were selected and participated in this study. Given this small sample size, the findings of this study cannot be generalized to the lived experiences of child protection workers in Southern Ontario. Participants were selected through a blind copy email (See Appendix A) sent to 10 child protection workers, who were contacted through their personal email. Since there was already some professional relationship with the participants, this helped me establish rapport and trust, which created the space for more open and participatory discussion during the interview process. The participants in this study all work for the same agency.

The years of work experience ranged between 2 to 25 years among the participants, which provided a wide spectrum of experiences, knowledge and practice between the participants.

\section{Data Collection}

Semi-structured interviews with open-ended questions were conducted with each participant in order to draw out the narratives. Interview conversations were informal and loosely structured based on the questions outlined in the Interview Guide (See Appendix B) in order to give participants as much control as possible over the amount of information they were willing to share. For the purpose of this study, data were gathered based on the experiences of the 
participants with regards to their practice as child protection workers. Narrative interviewing approaches were used that centered on participants' understandings of attachment theory and reflective practice, while using participants' language to deepen interview discussions while maintaining "a curious stance" (White \& Epston, 1990). As well, my intention was to focus on interaction and process rather than information gathering (Anderson \& Jack, 1991). During the interviews, ideas were occasionally introduced from the literature by the researcher, in order to facilitate clarity and discussion. Adopting this approach allows for the co-construction of the participants and their narratives, which challenges the traditional role of the researcher as the "objective observer" that is often used in positivist quantitative methods.

Consent was obtained from the participants (See Appendix C). Based on anti-oppressive principles, consent is seen as a formal contract that reflects research participants' right to a transparent research process and to as much involvement in the research process as they choose (Potts \& Brown, 2005. Each interview was audio taped with the participants' permission and were about one hour in length.

\section{Data Analysis}

This study engaged a critical discourse analysis (CDA) since the study explores the reproduction of power relations through the use of the dominant discourse of attachment theory, within child protection practice. A critical discourse analysis focuses on relations between power and discourse and how these relations are reproduced (Van Dijk, 1993), which is why this approach would also be an appropriate framework for analyzing the data. Conducting a CDA helps determine the dominance of attachment theory in child protection practice. Also, this is a necessary step to decolonizing dominant discourses that guide social work practices, which is 
why anti-colonial framework would fit into this analysis. Furthermore, Van Dijk (1993)

discusses the concept of "power and control" in CDA (pg. 553). This idea of power and control emphasizes the influence of social power in connection with power relations in society and further explores how meanings are created in relation to power and control (Van Dijk, 1993). Thus, the dominance of attachment theory within the child welfare system and this analysis of power in child protection, further informs institutional discourses and ideologies. Furthermore, van Dijk (1993) refers to institutional power and states:

The persuasive or manipulatory success of dominant discourses is partly due to the patterns of access of such text and talk. That is, most power elites are themselves white, and their power implies preferential access to the means of mass communication, political decision-making discourse, and the discourse of bureaucracy...(p. 86)

Within the standards and policies of child welfare, the creation of dominant discourse found in attachment theory was evident in the normalizing of the Eurocentric values and ideologies surrounding attachment. The institutional power of child welfare creating practice guidelines and assessment tools regarding attachment do not seem to reflect the social realities of marginalized and racialized families. This perpetuates the marginalization of these families by assessing parents against an unfamiliar standard. Through the use of institutional power and neutralized positioning of power, dominant discourses within child protection become invisible, yet these dominant ideologies are blended in throughout polices, standards and assessment tools, which is further supported and justified by using evidence based research. This use of power continues to apply attachment theory as a universal concept and perpetuates racialized disparities and unequal power relations within child protection practice and maintain systemic forms of neocolonialism by defining categorized lines of difference. 
Fook (2002) explains that "Foucault sees discourse as being made up of all the ways in which knowledge is constituted in society" (p. 64). She adds that "the language we use is therefore an indication of which value system or which groups are dominant" (Fook, 2002, p. 66). Discourse analysis is based on an understanding of how discourses shape meaning and in this study, understanding the discourse of attachment theory within child protection practice, will assist in understanding how society shapes what "normal" or "healthy" attachment or good parenting should look like. Discourses implicate us and shape our desires and our thoughts thus having a significant amount of influence on individuals and their behaviours.

The role of critical discourse analysis involves identifying the reproduction of inequality, through critically examining professional, institutional and dominant discourses that impact on various groups within society (Wodak, 1996; Mumby \& Clair, 1997). In this research study, dominance and power are looked at, by identifying the normalized role of attachment theory and its impact on marginalized populations. For instance, attachment theory operates as a dominant discourse in child protection practice, which disconnects the family from the theories behind the assessment tools used to make decisions around child welfare. Accordingly, these dominant ideas are revealed in the narratives of the participants who emphasize the importance of attachment theory in their practice. Thus, this study examines the discourses that arise from the participants' stories, which connects well with the narrative inquiry design.

The concept of attachment in child protection and assessments are essentially informed by Western psychology and Eurocentric evidence based research paradigms that positions itself as the gaze, which determines whether or not a particular attachment style meets the needs of a child, based on observations of parent/child interactions. Through my analysis of attachment theory as a dominant discourse within child protection practice, structural systems will also be a 
factor in how parents and workers are positioned. As a result, institutional power is conveyed through implicit and explicit meanings contained within the notion of attachment, which ignores issues of power differences. Accordingly, power is embedded within discourse and whoever controls the dominant discourse essentially controls the common understanding of attachment (Fook, 2002).

In summary, analyzing discourses and deconstructing our ways of thinking would result in unsettling the knowledge we produce as well as how we behave and interact; all contribute to constructing social relations and structures.

\section{Insider/Outsider}

As a social worker that has practiced child protection, I am positioned as having an outsider/insider relationship with this research. My own experiences and practice allow me to understand the complexities and challenges faced by child protection workers and how they cope with these challenges. Even though there may be similarities in some of our stories, I remained interested in how other child protection workers struggle or succeed in shaping their practice.

I felt connected to the complexities that the child protection workers have experienced, however, it is important for me to acknowledge my position as a "researcher" in this study and the positions of power that I hold, "It is about paying attention to and shifting, how power relations work in and through the process of research" (Potts \& Brown, 2005, p. 255). For instance, I may identify myself as an outsider but the participants may still consider me as an insider or even an outsider, which may or may not impact their responses. I remain aware of this position and acknowledge the importance of creating the space to reflect on my own experiences of the research process. Caroline Humphrey (2007) points out the importance of the 
insider/outsider role and discusses how it is better to be aware of your position as an outsider/insider before others become aware of it, in order to manage it and take charge of it "rather than becoming hostage to it" (p. 13). As well, Hamdan (2009) explains that there are many indications of being an insider/outsider, which can cause discomfort especially when revealing difficult situations, tensions and/or negative aspects of practice. As such, self-reflection becomes critical while conducting this kind of research. Hamdan (2009) continues to argue that reflexivity pushes the researcher into a space of discomfort, "the integration of reflexivity of discomfort into insider-outsider research is indispensable for transcending the distortions introduced by the various lenses through which researchers and research subjects view the world in general and the matters being researched in particular" (p. 378). I remember feeling anxious about interviewing the workers about dominant discourses that may or may not inform their practice. By deconstructing the policies and standards of the child welfare system rooted in dominant ideologies, I was concerned about being seen as the "other" and representing the workers as reproducing and reinforcing dominant discourses in their practice. On the other hand, this study has allowed me to explore the experiences of other child protection workers where some of the workers became engaged and started to become reflexive about their practice. As previously mentioned, I had to confront the difficult issue of power as an insider/outsider researcher exploring other people's experiences around dominance. Therefore, I chose to be reflexive in an attempt to investigate the power embedded in my research and to work towards eliminating it. I wanted the stories to really guide this study without the influence of my own experiences and biases. Hence, this research seeks to remain collaborative and transparent in both the process and outcome in order to ensure accuracy in how the narratives are represented. 


\section{Chapter 4: The Voices}

This chapter will discuss the narratives of three female child protection workers who formulate assessments around child protection concerns, in a city that is highly diverse and racialized. Pseudonyms have been used and some details of the participants' stories have been excluded to protect the participants' identity. The participants in this study are three racially diverse women who range in work experience from two to twenty-five years.

\section{Themes}

Four themes were derived from the interviews that were based on common concepts that emerged across participant narratives. The themes seem to correlate with how attachment theory is a dominant discourse within child protection practice and capture various perspectives on reflection and their practice; as well as individual challenges and struggles around their practice. The four themes are: attachment theory as the pinnacle; the gaze; standards and routine versus critical reflection; and fighting the stigma and engaging families.

\section{Attachment theory as the Pinnacle}

Participants discussed the importance of applying attachment theory in their practice and understanding it. Madeline discusses the knowledge gaps and training issues:

Since access is attachment based in the agency, we're well positioned in attachment theory. However, there are times when workers are not as conscious. There have been 
occasions when workers are really not aware of the importance of attachment between parents and children, whether it's healthy or unhealthy between a child and their parent...

Penny acknowledges the importance of attachment theory in identifying risk factors but feels that the theory is often not well understood:

I think there's recognition in child protection that attachment theory is a very important theoretical framework. I think there's that recognition and I think its ingrained. I think its behind a lot of the risks we have defined for children in terms of emotional care, in terms of risks for physical discipline or other abuse risks. But I also think that it's underutilized in this field. And I think there's not a lot of focus on or in our practices and procedures and especially in our training, on better understanding attachment, what to look for and how to assess it. Having the tools to be able to assess it, I don't think there's enough to understanding, or of sharing of that understanding...I think as social workers. We probably not everybody, but there's a percentage of workers who get it and understand the importance of it and understand that attachment assessment is really where they need to start. Then there are some who don't understand that model because they haven't been trained....

Penny continues to discuss some challenges in child protection. It seems that there is this expectation of being an expert on attachment theory and practicing it, but challenges around what is considered a qualified clinician in child protection:

Being able to describe it and explain your assessment in a way that's received with validity and importance can be challenging. So what I'm thinking about is, we have all this experience of observing all these families, observing attachment and doing our clinical training, but we can't then write a report to a court that says, this is the 
attachment style I observed. Because they don't see us as qualified to be able to label, describe and assess attachment specifically. And that's a really big challenge because we all know what we're seeing and we've had all of this experience, but it has to be sort of stamped by a psychologist or someone whose completed these trainings on the AAI for example or trained on the strange situation tool. So there's a lot of challenges around any assessment about attachment particular within child welfare.

Anissa shares similar views and discusses her knowledge gaps on attachment theory and the lack training provided:

Well, I think we are expected to assess attachment because if you think about it, these concerns are rooted in attachment. As well, we're expected to assess attachment between parents and their children however, I don't recall any type training or anything, or any type of dialogue on how to really do that. And maybe the assumption is that we learned that in school, which we did, but if it's expected for us to assess attachment then there should be some type of training or something...

Based on the responses of the participants it is evident that they struggle with knowledge gaps and training issues. They all recognize the importance of attachment theory but feel that the theory is not very well known within the agency.. There seems to be a strong desire for more training, which comes from fulfilling the expectations of knowing, performing and practicing attachment theory and for them to get it right. Anissa expresses this further and adds:

And I don't really feel like attachment even though it's such a pinnacle it's so important and we learn about it in our undergrad, or in our masters but I don't know if we learn about it or if its talked about in depth, at work. Do we have training for it, I don't know. Maybe the new worker training there is attachment training I don't know, 
but I don't remember any of that so here we are. You know some of us are parents and some of us are not so that really impacts things...I don't know, how well are we doing our assessments, how well equipped are we to do these assessments on "attachment"? All I can say is that it's a crucial part of our assessments and I think, I wish I understood it a bit more actually. Now that I'm thinking about it, I think its crucial yeah, because if we can at least foster healthy attachment then maybe we could address some of the worries. Anissa indicates that she does not understand attachment theory and wants to learn more about it. All the participants share this notion of gaining more knowledge with regards to attachment theory, since it plays a key role in their practice and is also used to make decisions. Therefore, attachment theory is positioned within child protection as a "universal truth", which does not expose the Eurocentric values attached to its usage. Furthermore, attachment theory is reinforced in child protection, which is viewed as a pinnacle that workers are trying to work towards and understanding more about it, in order to incorporate it more into their practice and being competent in their work.

\section{The Gaze}

During professional development training, workers learn about the standards, policies and procedures to child protection practice. As a new worker, you are assigned to a senior social worker for mentoring and modeling purposes and a supervisor is available for consultation and guidance. Thus, all of these stages experienced by new workers emphasize the assessment of risk of harm to a child, which is well rooted in assessing attachment relationships between parents and their children. Here, the workers express how attachment theory is used through access and observation. Madeline states that: 
Observations, what you see in the relationship between a child and a parent is important and usually these observations take place during access visits, if the child is in the care...so we are constantly assessing...

Anissa adds:

...well if the children are in care and there is access in our office, we're going to see, how the child responds to the parent. So observing the cues, if it's a baby for example, is there eye contact? Is the baby following the mom's eyes? Or is he crying all the time? Does the baby appear to be stressed? Or is the parent able to handle that? So looking for that natural bond...is the baby responding to the parent?

Penny also states that:

...observation and observing families and patterns of interactions and being creative in that observation. Allowing for natural stress to occur so that you can see attachment happen. So just that observation and setting up your work, your time with the family to allow for those natural stressful periods. Increasing their time together, increasing the transitions they have increasing the tasks parents have that in itself is a way to be able to assess that during access...I think just observation and I think that's where our assessments come a lot from and observing parents with their kids, how parents behave, what their lifestyles are, all those kinds of things. This is a big part of what we do and we are constantly assessing for attachment and risk...

Clearly, access is a significant component of assessing attachment and risk in child protection, where the participants are constantly assessing and performing the gaze as a part of their 
practice. The workers also discuss alternative perspectives to assessing attachment as Madeline articulates:

I think like everything, attachment in it of itself is not the only thing. When you look at the fact that this little girl has two brothers and in trying to work with the family a lot of cognitive theory is used, a lot of behaviour theory is used. Because the children are so out of control and now that you're pulling in different theories to set up structures and routines for the children in the home, in order for the parents to be able to start to attach to their children...

Penny introduces other assessment tools and states:

Well, obviously, there's [sic] more structured assessment tools like a Parenting Capacity Assessment (PCA), which depending on your assessor really does take into account an attachment focus and attachment theory. Alternatively there would be psychological assessments, which would have more structured valid tools other than the Adult Attachment Interview (AAI), cognitive testing and those kinds of things that helps us understand parents. And again, focusing on observing attachment which is where most of the assessments come from...

Anissa indicates that attachment theory is the only approach utilized by CAS:

Can we take it out in the community? Could family members assess for us? But they don't know about attachment theory so I think maybe a team that is specialized in this area that is mobile because, I think if we were able to, as closely as possible and assess families that are in our care obviously in their own comfort zone and their own 
environment I think we might be able to get a better picture...I'm sure there are alternatives but I don't think the agency utilizes that...

Participants discuss similar paradigms and acknowledge other theories that assess risk and require psychological and cognitive testing. However, most of the assessments come from attachment theory, where observation is the primary tool that is emphasized in the policies and standards of the Ontario child welfare system. It is clear that workers question the quantity of training provided and their knowledge about attachment theory. On the other hand, they recognize the importance and meaning of including it in their practice, since there are many expectations to using it.

This use of surveillance puts pressure and expectations on parents to perform attachment styles that are justified and explained to them by child protection workers. Despite these unfair expectations on parents within the child welfare standards, workers also are expected to assess attachment and risk. Accordingly, these assessments inform decisions regarding the best interest of the child. Although workers believe that attachment theory is not widely understood or utilized, there are different concepts of attachment theory and child development theory being used in child welfare practice, where attachment theory continues to hold its dominance. This is evident in the policies and procedures of CAS, which, according to the participants, emphasize the use of attachment theory. Also, the policies and procedures specifically include attachment theory training within the agency, as opposed to other perspectives and theories being used.

\section{Standards and Routine versus Critical Reflection}


Participants emphasize the importance of reflection as an ongoing process in their practice. As well, the workers also reveal the importance of having the space and opportunity to reflect, which is often during supervision. Penny shares:

I think supervision in itself requires you to stop and think because, you have to stop and think. And explain it to your supervisor and reflect with them about what the best decision is. However I think my experience with access and working directly with families, your time can be limited. Your stress levels can be high and the pace of the work can then eliminate those possibilities to really reflect on your practice, reflect on their situations and really have that opportunity to be more reflective.

Penny continued and discusses how new knowledge and new ways of practice can develop through reflection:

...I was actually at a clinical training yesterday and I find those days are opportunities to really reflect on your practice and what you're doing. How you can incorporate new clinical practices and how you can incorporate research. I become so reflective at those times and then you come back to work and it's gone. I know it's happen to me several times where I will take really great notes of how I want to use these ideas, and how I can use the clinical information and apply it into my practice. And then it's like, you just never get a chance to go through that and to be able to really build on those concepts, to have the time to say okay, I learned this and here is how I can break it down into my practice. Yeah its challenging, but I also think you have to be able to reflective in this work. You have to be able to take the time and say, is what I'm doing right now the best approach for this family? Is there something else I can learn or do or approach I can take, to be able to better this family? I think you have to do that, even though the timing is 
limited because the work is so fast pace and stressful. But I think you have to be able to build that into your practice.

Anissa links reflection with self-care:

...it's extremely important to reflect on how your social location is effecting a situation.... and if you're not reflecting you could be missing a very minor/major piece in engagement. So, yes, reflection is a part of child protection...To be quite honest I don't really reflect on every single case since the space is not there for me in my professional life. I think it's something I choose to do on my own, for me and for myself because I have to reflect. It's my way of self care, you know. But I can't say that the agency really provides a safe space for us to be able to reflect, or even the time to be able to do that because we're go, go, go...we can't give the same amount of attention to every single case. Generally, the idea of reflection and self-care, although it's supported, there is no time for it really...

Madeline, on the other hand, relates reflection to complex cases and triggers:

I had an exceptionally challenging caseload in the late 90 s and nearly all the children on my caseload were in care. So, I started to really use this as an example because it's really a time of strong reflection and my supervisor and I make decisions together. So we sat down and actually we reviewed my whole caseload at that time, in terms of kids coming into care and it was just the nature of the caseload. It just seemed to fall apart, we talk about a "black cloud" in child protection and it just seems that everything goes up and you don't have much control over those kinds of things, but it does make you stop and think... what is it that I'm contributing to the situation? Is it my thinking? Am I not as open as I need to be? I had a case where a father triggered me 
so I went to my supervisor and said that there was a situation. I needed to really sit down and think about this particular family and we agreed that we would sit and discuss it more during supervision and look at, what it was that was triggering me? So I would have to reflect...sometimes parents for some reason do trigger you and you have to reflect on that. For example, there was a mother and I had to really reflect on not getting sucked in to the dynamics that she would set, because in every situation she would set up some sort of conflict. So that was her issue and I constantly had to sit down and speak with my supervisor about how to manage situations, so I wouldn't get pulled into the conflict. So even with all my cases you have to somehow figure out what it is about some cases. To me some cases are little bit easier than others but when you're really dealing with borderline personality disorders, when you're dealing with really aggressive substance abuse individuals, where there's a lot of manipulation, you really have to do a lot of self reflection work. And then there is also my own personal issues where maybe another kind of case would trigger me and wouldn't trigger another worker. Yeah so there's lots of reflection that goes on...through reflection you put things in perspective...

Penny also indicates how experience can have an impact on reflection:

As experience grows my confidence has grown as a worker. The more experience I've had in this work it does become a little more natural because you've been in similar situations, and you've blurred all this clinical stuff and it becomes ingrained. Ironically the training I did yesterday was about the brain, and I think your brain starts to put these skills, practices and theories into that file fax in your brain and withdraw on them faster then when you're still learning. 
In addition, Madeline points out the shift in child protection practice:

When I started it was much more relationship oriented, today it really has become more accreditation and more focused on accredited clinical accreditation. Yes, it's run by standards and discretion has been removed, more so than you were able to use discretion before. And I agree that we need to have some kind of standard, but you can't rubberstamp families throughout, since there are always unique situations...

Clearly, participants speak of reflection in different ways. Madeline tends to self reflect about her practice and implicate herself. Penny sees reflection as a way of learning and gaining new knowledge in relation to how she can enhance her practice, while Anissa sees it as a way of self care and links it with social location and engagement. None of the participants could recall a time of confronting or disputing dominance, due to a lack of critical reflection, which reinforces and reproduces dominant discourses. Penny pointed out the need to apply different clinical theories in practice, which gets easier with experience, especially when faced with similar situations. Accordingly, practice can become routinely where reflection and discretion become minimal.

\section{Fighting the Stigma and Engaging Families}

Participants discuss the challenges in their practice, which encompass workload issues and engaging families. Anissa talks about this further and states:

...I think the stigma from the past has really shaped the way the community feels about the Children's Aid Society. I feel a lot of the work that I do with clients is debunking some of those myths and then also owning the fact that I am working within the system...I would have to say engaging with families is very challenging. I think that the way we go about things is a little bit intrusive, even though we are trying to have a 
customized approach, but we still carry a lot of power in what we do. So I think my number one or the number one challenge is engagement, but I do have to say the caseloads are extremely high and that really does impact the quality of work you can do. There's a never-ending amount of work that needs to be done.

Penny shares similar views as well:

There are workload challenges definitely and there's never enough time. The work is pretty constant and that comes from lots of different demands in competing areas...so workload is definitely an issue. And then I think there are challenges around resources, is, lack of resources. Things like, if you're working with a family and they might be engaged in the work, but they really need work else where like counselling for example. That's a big one because if there's not that resource available, you get kind of stuck and in child welfare we have to make decisions within a period of time. So the family might suffer because that resource isn't available to them. So that I think is a really really big challenge. As well as challenges like systemic stuff so there's just a lack of services and particularly financial resources for families, which become such a huge challenge. So, they might be doing the work, doing really well, but then there might be a housing issue for example or a poverty issue that they can't overcome that creates challenges for their family.

And Madeline conveys:

I think the biggest challenge isn't so much in dealing with the families but having to stay quiet about a lot of things. When I say that I mean families can get angry with you and you have to stay quiet. They are always accusing you of always trying to take their children, when in fact you're trying to work with them. It's trying to get beyond the 
pathology of their thinking, where they have a script in their mind, which is the struggle to work with. And you see the same things happening over and over again within the same family and it's really hard to work with the family. If they are not ready to address some of their own emotional issues and start dealing with their issues, it's hard to make change. As they are struggling, these mixed emotions they are projecting onto you and yelling at you and accusing you of being the problem in their life. So I find that to be the greatest challenge.

Madeline continued:

...the general public doesn't understand what it's like to be a child protection worker, so in discussing with people who don't know, they are surprised to find out that we do assess families. And when we look at the dynamics within the family, keeping the focus on the child and trying to ensure that a child is safe and how hard we work to keep the child in the family. I think that perception from the public is more that we just remove children and then try and sort out what's happening afterwards...There are occasions when you do get some feedback from the community and I think it's really really important to maintain those connections and help the community understand what's going on...so that dialogue is really important in the community. Workers seem to be bombarded with following the polices and standards of the child welfare system, along with keeping up with high caseloads demands and dealing with numerous families that resist involvement, due to the stigma of CAS. Consequently, this limits their opportunity to challenging the dominance of attachment theory. 


\section{Chapter 5: Analysis}

The four themes that emerged from the narratives support some of the knowledge earlier discussed; they also provide insights on child protection practice. The participants' experiences are consistent with some of my own thoughts and experiences as a child protection worker, which were among the factors that motivated this study. These factors include the lack of resources for families, demanding deadlines and high caseloads, reflecting on practice, as well as competency issues and engaging families.

According to the workers in this study, attachment theory plays a significant role in their practice. This supports the literature on how attachment theory influences child protection practice (Neckoway, Brownlee \& Castellan, 2007; Sinclair, 2004; Howe, Brandon, Hinings \& Schofield, 1999).

The findings of this study suggest that the participants are expected to assess attachment, which is usually applied universally without being challenged where dominant discourses are reproduced.

The first theme speaks to understanding and working towards the pinnacle of child protection practice. Workers express the need for more knowledge and skills regarding attachment theory, as well as conducting assessments and formulating reports. Penny shares her thoughts about the challenges of being a qualified clinician, which means using attachment theory to conduct clinical assessments on attachment. As mentioned earlier, this speaks to the professional expectations of workers. According to the CASW Code of Ethics (2005), one of the core values guiding social work practice is competence: 
Social workers respect a client's right to competent social worker services. Social workers analyze the nature of social needs and problems, and encourage innovative, effective strategies and techniques to meet both new and existing needs and, where possible, contribute to the knowledge base of the profession. Social workers have a responsibility to maintain professional proficiency, to continually strive to increase their professional knowledge and skills, and to apply new knowledge in practice commensurate with their level of professional education, skill and competency, seeking consultation and supervision as appropriate. (CASW, 2005, p. 9)

Additionally, in child protection, the standards for competence in knowledge and skills are clearly defined as social work degree qualifications, knowledge of the Child and Family Services Act, child development, parenting issues and policies, and skills pertaining to case-management, achieving permanency and focus on prevention, to name a few(CASW, 2005). Thus, it is crucial for workers to have continuous training to strengthen and increase their knowledge and skills, while engaging in best practices. The idea of meeting all these expectations relates to the notion of being professional. This idea of being professional in practice indicates how the professional perspective is constructed in a dominant society, as being objective and scientific (Powell, 2012).

The findings of this study suggest that child protection workers rooted in discursive institutions such as Children's Aid Societies, function according to particular expectations around performativity. Butler (1993) explains, "performative acts are forms of authoritative speech, most performatives, for instance, are statements that, in the uttering, also perform a certain action and exercise a binding power" (p. 225). Powell (2012) suggests that performativity also provides a basis for analyzing the complexity of professional practice where a single practitioner undertakes different roles, often with different value bases, in different contexts. A particular example of this is evident in social work assessments. According to Powell (2012), three models of social work assessments, "the questioning, procedural and exchange models position social workers differently in relation to the client, the social context and the 
organization" (p. 75). As a result, "questioning and procedural models place the professional as expert, the organization as authoritative, wants are distinguished from needs which are defined a priori, outcomes are privileged and the client/service user is passive and dependent" (Powell, 2012, p. 75). In addition, assessment tools such as observation and access, lead child protection workers to making decisions and determining the best interest of the child. As previously discussed, access is a form of surveillance, which creates power imbalances between workers and parents involved in child protection. Since workers are mandated by the policies and standards of the child welfare system, workers are positioned in an expert role and make all the decision around assessments and family situations, which often marginalizes clients. This systemic marginalization exposes racialized parents in particular to increased vulnerability by subjugating them to the practices of Eurocentric ideas sanctioned by policies within child welfare institutions.

Analyzing from a critical discourse lens, it is evident that power and discourse play a significant role in child protection as well as in social work practice. For instance, attachment theory operates as a dominant discourse in child protection practice, where the theory has been adopted and normalized in practice, thus reproducing colonial relations. As well, "theories of social work practice create the space for performativity, shaping the identities of participants as subjects while subjugating that identity within communicative structures of organizations" (Powell, 2012, p. 75). This creates power inequalities, where service providers are positioned as the expert and service users are dependent on the worker/agency, which is significant in social work practice and in child protection practice.

It is evident that attachment theory plays a significant role in the Ontario child welfare system and practice. Positioning attachment theory as a "scientific truth" leaves little room for it 
to be challenged. The participants in this study described how they are expected to assess attachment even though they may not fully understand it. Participants also discuss similar paradigms such as psychological assessment tools that are used to assess attachment styles and risk. This connects to the assumption that Western/Eurocentric knowledge is universal and applicable to everyone. Thus, assessment tools in child welfare are created using white Eurocentric norms and standards, which marginalize non-Western families (Strega, 2009). Workers are positioned as representatives of social control who determine the existence of attachment, the attachment styles permissible and what will be considered as risk. As well, the importance of family engagement and collaboration is supported, however, within the standards and policies of child welfare, power is clearly restricted to the domain of the worker and the use of power is centralized (van Dijk, 1993).

Embracing an anti-colonial lens allows me to understand how attachment theory does not recognize colonization as a historical phenomenon, but rather continues to impact and create colonial relations on racialized and indigenous communities (Dei \& Asgharzadeh, 2001). The acknowledgment of colonial relations is important in child protection due to the history and ongoing role of child protection involved with vulnerable populations such as Aboriginal communities in Canada (Blackstock, Trocme \& Bennett, 2004). This recognition with regards to attachment assessment tools should impact on how power relations are mentioned, in relation to the communities that are being served and will require the removal of power to reflect the implications of client/worker relationships. This is required in order to unsettle existing power imbalances and their impact on racialized communities. In order to move towards transformative ways of assessing from an anti-colonial and anti-racist paradigm, change within child protection standards and polices should be reflected in institutional and systemic processes and should not 
be viewed as being the parent's responsibility. Within attachment assessment tools, there is no reference to marginalized or racialized communities in relation to other forms of attachment practices, which silences these communities. In this way, whiteness is allowed to continue occupying a position of dominance, while the marginality of racialized members of the community continues to be reinforced as powerless (Razack, 2002). Therefore, it is important to note that we cannot always be assessing from one dominant lens.

An additional theme that emerged was the use of reflection in child protection practice. Some participants share how reflection is linked to decision-making and consultation during supervision. Participants expressed how they are mandated to consult with their supervisor at least once or twice a month with regards to reviewing cases, in order to make decisions. This is an opportunity for workers to reflect and discuss challenges and tensions they may encounter.

This reinforces and implies that a positivist theory such as attachment theory is objective, which limits the consideration of other theories around attachment, since the truth of the theory transcends perspective. Consequently, the theory continues to be reinforced in practice and rarely challenged. Since there is so much at stake workers tend to be concerned with gaining more knowledge, about their social location, liability and competency issues rather than implicating themselves in their practice.

The idea of reflective practice involves reflexivity, which combines both social critique and personal reflection. Reflexivity allows workers to engage in critical self-reflection, "reflecting critically on the impact of their own background, assumptions, positioning, feelings, behaviour while also attending to the impact of the wider organizational, discursive, ideological and political context" (Finlay, 2008, p. 6). According to the findings, the workers tend to understand reflection in different ways. For instance, Madeline is able to engage in critical self- 
reflection and discusses triggers and personal issues that may have an impact on her practice. She does this by implicating herself and asking questions about what she may or may not be contributing to when working with families, formulating assessments and making decisions. On the other hand, Anissa and Penny see reflection as a time to step back and reflect on particular cases without the use of any reflexive approach rather focusing on social location and applying ready made knowledge to practice. Anissa recognizes that reflection is supported in child protection practice but being critical and reflexive is not really practiced. As well, it seems that workers are not familiar with the understanding of being reflective in practice. Heron (2005) explains the importance to clarifying the differences between social location and subject position that exist and the relations of power that are operating between parents and workers.

As well, it is important to note that institutions embody the practices, assumptions and values of dominant discourses, which influence practice. Child protection workers often work in demanding, pressurized environments, where space and time are limited and reflection is practiced without being critical or reflexive, which can reinforce dominant ideas. This makes me think about the assumptions and stereotypes associated with attachment that inform the service provided and decisions made while involved with CAS. Taylor (2006) discusses the notion of practice becoming mechanical and routine like, which limits critical reflection, which was evident in participants' narratives. As well Taylor (2006) indicates how reflection, critical reflection and reflexivity are often assumed to be interchangeable and confusing. For instance, workers have emphasized the importance of reflection in practice and assume to being critical when in fact, universal theories are being applied across families, without a critical perspective on policy and practice. 
Lastly, the workers discuss many similar challenges in their practice that involve the community's perception of child protection, which has negatively impacted on the process of engaging families. The child welfare system continues to be associated with oppression experienced by marginalized groups in society such as the aboriginal community.

Workers also emphasize the importance of engaging families in their practice. This links to strengthening the relationship between workers and parents and building rapport, which evidently has positive impacts on service plans being met. For instance, when families are engaged, parents are more likely to recognize and agree with the identified problems to be resolved, perceive goals as relevant and attainable, and be satisfied with the planning and decision-making process (Healy, Darlington, \& Yellowlees, 2011). This connects to how colonial relations are formed. Social work, as a discipline, has created subjectivities relating to service users and service providers. This is especially true within the child welfare system, where agencies are tasked with managing the behaviour of defiant parents to avoid the abuse of children (Schmid, 2009). However, for parents who resist and are not engaged during their involvement with child protection, they challenge the dominance they experience from workers who are lead by regulated practices. As well, workers are constantly coming across complex family issues, large workloads and liability issues, but more focus tends to be towards building relationships and complying with polices rather than reflecting on and challenging the dominance of attachment theory.

Moreover, subjectivity is a way in which institutions maintain power and disciplines individuals (Tamboukou and Ball as cited in Schmid, 2009). Schmid (2009) states "subjectivities are one mechanism used by social workers to assert and maintain dominance over clients. This control is not necessarily applied intentionally by individual social workers but 
becomes a function of the child welfare system" (p. 94). As dominant relations are formed, parents are expected to follow through and comply with service plans and decisions, which reinforce universal dominant ideas. Institutional power functions through particular constructions of the service user, where the service user is constructed as "the client". This masks the fact that involvement with the child protection system is seldom voluntary and "typically is cast as the failing or inadequate parent. This stance justifies intrusive investigation” (Schmid, 2009, p. 94), where the child welfare system functions to reinforce dominant, middle class ideas of family life (Reich 2005). Therefore, workers will continue to encounter challenges around engaging families due to regulated practices and procedures that are mandated in the child welfare system. 


\section{Chapter 6: Implications for Social Work}

This study explores the concept of attachment theory that is represented as a dominant discourse in child protection. The study also examines attachment theory as an assessment tool that perpetuates colonial relations by presenting attachment theory through a pathologized lens, which disconnects marginalized and racialized families. This research illustrates how Eurocentric views of attachment reinforce dominant discourses and reproduced colonial relations. Furthermore, the study indicates how attachment theory reproduces dominance and inequality, which subjugates families by conveying a neutral stance with regards to the impact of institutional power and assessing attachment through the use of pathology. Moreover, the work of child protection practice is often examined through a lens of dominance, which concentrates on Eurocentric world-views (Strega, 2009).

The findings of this study provide great insights about how attachment theory is a ruling discourse in child protection practice. The experiences of the participants in the study suggest that considerable weight is placed on attachment theory in child protection practice, where critical reflection and reflexivity are blurred with reflection. As well, workers feel that there is not a full understanding of attachment theory, they recognize the importance of it and are required to use it in their practice.

Currently, child protection agencies have fostered different ways to address concerns regarding the disproportionate number of racialized and Aboriginal children in care within the child welfare system. Child protection agencies are beginning to understand the significance of this and implementing new policies and trainings in order to increase reunification and reduce 
children coming into care. This would be an opportunity for the child welfare system to encourage and support workers in engaging in reflective practice.

Given that child protection workers have decision-making power that come from organizational policies, it is important for workers to accept and commit to an anti-colonial perspective in their practice. This means implicating social and institutional structures that maintain and perpetuate inequalities, which includes colonialism. An anti-colonial framework requires the child welfare system to implicate these structures in the ongoing practice of colonialism and provide new perspectives and transform the system that continues to perpetuate inequality. We would then be able to debunk the complexities and difficulties that underlie the disproportionate patterns that exist in the Ontario child welfare system.

Furthermore, transforming the field of child protection requires the deconstruction of policies and procedures and their impact on practice as well as the families involved within the child welfare system. Acknowledging and recognizing the colonial relations within child protection is an important stage towards transforming practice. As well, questioning the universalizing norm of Western ideas in the concept of attachment is the first step towards unsettling dominance in the child welfare system (Kincheloe, 1999). Anissa, one of the participants in this study, begins to unravel this and points out the limitations of attachment theory:

I'm sure there are alternatives but I don't think the agency utilizes that because attachment theory comes from a Western Canadian, the paradigm or whatever, of what attachment is. So this might not be the same for an African family or a West-Indian family, what does attachment in their culture look like? But it's the only tool that the agency pushes and yet it's not all encompassing. 
Therefore, highlighting cross-cultural meanings of parenting insights to ethnotheories about the early stages of life and attachment, challenges attachment theory. This approach aligns with anti-oppressive and anti-colonial practice since it challenges norms and dominant discourses of attachment practices. Thus, challenging institutional barriers and regulated practices would support cross-cultural practices in order to improve services for marginalized families.

In conclusion, taking a critical stance and decolonizing attachment theory will involve addressing and challenging the privileged epistemology that currently exists, and recognize other forms of knowledge production and ways of knowing. This might bring awareness to new and different possibilities of practice relating to child protection and inclusivity. This might also aid in developing a better understanding and greater possibility for service delivery, towards engaging families in a way that does not reproduce or perpetuate colonial relations. The purpose of challenging and decolonizing attachment theory is not to abandon attachment theory and replace it with another dominant theory, rather to reflect on practice and acknowledging other ways of knowledge and practices of attachment and to not see them as inferior or unsafe practices.

However, given that child protection is a regulated practice, resisting and moving away from a universally applied theory such as attachment theory would create many challenges. Since attachment theory seems to inform child protection practice and so much emphasis is placed on it, it would be difficult to interrogate. Being a protection worker I also acknowledge the fear that comes with resisting the dominance of attachment theory and trying to introduce and implement new possibilities for practice. Due to fears of liability issues and institutional power, I remember 
not trying to astray from the mandated policies and procedures, because the last thing a child protection worker wants is a death or abuse of a child on his/her caseload. If a worker is already working with a family and a child is abused or maltreated, an investigation will be conducted to ensure that the worker was compliant with the appropriate policies and procedures. If the worker was not compliant with the policies and procedures and alternative methods were used without the knowledge or permission of the supervisor, then the worker can be held "civilly or criminally liable for inadequately protecting the child by failing to accept a report for investigation, failing to conduct an adequate investigation or failing to place a child in protective custody" (Kamani, Regehr \& Bernstein, 2002, p. 1031). As a result I avoided any sort of negligence on my part and complied with the standards and polices provided by the agency. Unsettling the dominance of attachment theory can also have negative repercussions on workers who resist this dominant discourse, where they could potentially loss their job.

As I return back to work in an environment highly influenced and guided by standards and polices of the Ontario child welfare system, how will I continue to support families and their children, while facing all of these challenges? Aronson \& Sammon (2000) discuss the notion of "small victories", in a study conducted with social workers in front-line practice who encounter many challenges, tensions and contradictions in their practice, due to time constraints, managerial forms and fragmented effects of divided labour (p. 167). Victories can be referred to as "practice moments that are valuable reminders of the significance of time and resources starved interventions both for clients' welfare and for workers' sense of efficacy" (Aronson \& Sammon, p. 182-183).

I remember many clients \& community agencies that appreciated working with me due to my commitment to going the extra mile for clients. From my experience, working with 
community agencies in order to support clients, made a difference in having successful outcomes for clients and my sense of accomplishments. Access to services often required a letter of support from an agency such as CAS and researching, letter writing and advocating for clients were some of the tasks conducted, in order to getting services or access to childcare, camps and other services. These were successful moments for me, especially when the client was able to receive the appropriate services required. These successful moments of assisting clients in navigating or manipulating a system that we are all resisting, in some way shape or form, can be seen as my "small victories" that will sustain me. 


\title{
APPENDIX A: Recruitment Email
}

\section{EXPLORING DOMINANT CHILD PROTECTION DISCOURSES: NEW POSSIBILITES FOR PRACTICE}

\author{
Seeking Participants for Study about child protection and practice.
}

My name is Nimo Samater and I am currently completing a Master of Social Work degree at Ryerson University. I am in the process of recruiting participants for a small study exploring the experiences of child protection workers and some of the challenges they may encounter during practice. Please note that this study has been reviewed and approved by the Ryerson Research Ethics Board (REB).

More specifically, this study will explore the role of attachment theory and how parents and child protection workers are positioned within this theory. Attachment theory suggests that a key developmental task of infancy is forming an attachment to the mother or primary caregiver. Bowlby believed that attachment relationship is biologically rooted and functions to promote the infant's survival (Mennen \& O'Keefe, 2005). In the interview I would like to discuss how you use attachment theory and how you understand it. I hope that this study will allow you to have the opportunity to share your stories, reflect on your experiences and challenges as a child protection worker. Eligible participants will have at least one year of experience as a child protection worker.

The interview process will involve a one-on-one interview in a location of your preference. The location of the interview can be at any convenient setting of your choice or in a private room at Ryerson University. If you agree to be a part of this study, you will be asked to participate in a audio recorded interview that is approximately 1-1.5 hour, where you will asked to reflect on your practice as a child protection worker while forming assessments. This will allow for the opportunity for reflective practice, which has been described as associated with attempts by practitioners to distance themselves from their experiences and thereby achieve a more objective view of their practice (Kondrat in D'Cruz et al., 2007).

Topics that will be explored include attachment theory / the exploration of reflective practice / any changes with regards to practice over time in your own understanding of your practice. In addition to this there will be questions around the context of practice, perspectives on practice as well as the role of attachment theory in child protection.

All information shared will be confidential and no names or identifying information will be published or shared in any way. Participation is entirely voluntary and you can choose to end your involvement with the study at any time.

For more information please contact me at nsamater@ryerson.ca or 647-981-7493. I look forward to hearing from you.

Thank you,

Nimo Samater

MSW Candidate, 2014 Ryerson University 


\section{APPENDIX B - INTERVIEW GUIDE}

\section{EXPLORING DOMINANT CHILD PROTECTION DISCOURSES: NEW POSSIBILITES FOR PRACTICE}

The interview will be conducted in a narrative style and will involve a conversation between the investigator and the participant. However the following questions will be used to focus the interview on the topics that surround child protection practice and attachment theory.

Thank you for participating in this study. I would like to inform you that this interview will take approximately between 1 to 1.5 hours. I also want to emphasize that everything you say here is confidential and that I will be the only person to have access to the information you provide, with the exception of my research supervisor. All identifying information will be removed from your transcript and aliases will be used if you are quoted. Additionally, I would like to ask your permission to record the interview. At any point during the interview, you may ask to stop the recording or take a break. You can also terminate the interview at any point if you feel any discomfort or you decide to change your mind about being part of this research study. Do you have any questions before we begin?

1. How long have you been a child protection worker?

2. How did you become interested in child protection work?

3. What is like to be a child protection worker?

4. What are some of the challenges you have faced as a child protection worker?

5. Based on your experiences has child protection changed? If so, how? Can you give some examples?

6. Based on your experiences do you find that you work differently with different demographics? Can you give me some examples?

7. Is a reflecting process or any kind of reflective work involved in child protection practice?

8. Would you say that you reflect on the work that you do? If no, why and has this impacted your assessments or you relationship with families and children? If yes, have there been any impacts on your assessments and relationship with families and children?

9. What are some of the common ways of assessing attachment? Are there any restrictions?

10. Are you familiar with attachment theory?

11. How is attachment theory positioned in child protection?

12. What are you views about attachment theory? 
13. Other alternative methods or tools used to assess parenting and attachment? What are some examples?

14. Can you give me an example where a parent is not attached to his or her child and another example where the parent is attached?

15. What informs your practice as a child protection worker?

16. Is there anything else you would like to share? Anything I didn't ask about that you think is important? Do you have any questions for me? 


\title{
APPENDIX C: CONSENT FORM
}

\section{RYERSONUNIVERSITY}

\author{
SCHOOL OF SOCIAL WORK \\ FACULTY OF COMMUNITY SERVICES \\ Accredited by The Canadian Association for Social Work Education
}

Exploring Dominant Child Protection Discourses: New Possibilities for Practice

You are being asked to participate in a research study. Before you give your consent to participate, it is important that you read the following information and ask as many questions as necessary to be sure you understand what you will be asked to do.

\section{Investigator:}

Nimo Samater - Master of Social Work Candidate, Expected Date of Completion: August 2014

\section{Supervisor:}

Susan Silver PhD - Associate Professor, Ryerson School of Social Work

Purpose of the Study: This research study is an exploration of the role of attachment theory in child protection practice and how parents and child protection workers are positioned within this theory. Attachment theory suggests that a key developmental task of infancy is forming an attachment to the mother or primary caregiver. Bowlby believed that attachment relationship is biologically rooted and functions to promote the infant's survival (Mennen \& O'Keefe, 2005). I hope that this study will allow you to have the opportunity to share your stories, reflect on your experiences and challenges as a child protection worker. In this study I will be recruiting three child protection workers and eligible participants must have at least one-year work experience in child protection.

Use of Data: The information gathered and shared by participants during the interview process will be used for two purposes. The first purpose is for a supervised Major Research Paper submitted to Ryerson University in completion of a Master of Social Work degree. The second is that the data might also be used for publication in a peer-reviewed journal.

Description of the Study: The data collected during this study will involve a one-on-one interview and the demographic data that is collected is the number of years of work experience as a child protection worker. The location of the interview can be at any convenient setting of your choice or in a private room at Ryerson University. If you agree to be a part of this study, you will be asked to participate in a audio recorded, approximately 1-1.5 hour interview, that will ask you to reflect on your practice as a child protection worker while forming assessments. Topics explored will include attachment theory / the exploration of reflective practice / any changes with regards to practice over time in your own understanding of your practice. 
Please initial here to indicate that you have read this page:

Please sign here to indicate that you consent to being audio taped during your interview:

$\mathbf{X}$

Risks or Discomforts: You might experience discomfort during the interview due to the topic of discussion and the length of the interview. Please note that you can stop the interview, withdraw or take a break at any point during the interview process or after it has taken place. If you decide to withdraw, all data collected from you will be destroyed and will not be included in the study. I will offer all participants referrals to community resources.

Benefits of the Study: I hope that this study will allow you the opportunity to reflect on your practice as a child protection worker and to have this experience heard. I hope that this research will help increase the use of reflective practice while assessing family situations. However, I cannot guarantee benefits from participating in this study. Reflective practice has been described as and associated with attempts by practitioners to distance themselves from their experiences and thereby achieve a more objective view of their practice (Kondrat in D'Cruz et al., 2007).

Confidentiality: Only the student investigator and their supervisor will have access to the data collected. The data from interviews will be audio recorded and transcribed by the investigator. All identifying information will be removed from transcripts and aliases will be used to ensure confidentiality. Transcripts and electronic recordings will be password protected, stored at Ryerson University and deleted after 5 years.

Voluntary Nature of Participation: Participation in this study is voluntary and there is no compensation or incentives offered to participants. Your choice of whether or not to participate will not influence your future relations with Ryerson University. If you decide to participate, you are free to withdraw your consent and to stop your participation at any time before the final report has been written. At any point in the study, you may refuse to answer particular questions or stop participation.

Future Contact: If you consent to be contacted for the purpose of sharing the study findings, you will be contacted when the study is complete via email or phone, as you prefer.

\section{Email address or}

Telephone number

Questions about the Study: If you have any questions about the research now, please ask. If you have questions later about the research, you may contact.

Investigator/Study Coordinator:

Nimo Samater - (416) 979-5000 nsamater@ryerson.ca

Study Supervisor: 
Susan Silver - (416) 9795000 x6216 ssilver@ryerson.ca

If you have questions regarding your rights as a human subject and participant in this study, you may contact the Ryerson University Research Ethics Board for information:

Toni Fletcher, Coordinator, Research Ethics Board

c/o Office of the Vice President, Research and Innovation Ryerson University

350 Victoria Street

Toronto, ON M5B 2K3

416-979-5042 / rebchair@ryerson.ca

Please initial here to indicate that you have read this page:

\section{Agreement:}

Your signature below indicates that you have read the information in this agreement and have had a chance to ask any questions you have about the study. Your signature also indicates that you agree to be in the study and have been told that you can change your mind and withdraw your consent to participate at any time. You have been given a copy of this agreement.

You have been told that by signing this consent agreement you are not giving up any of your legal rights.

Name of Participant (please print)

Signature of Participant

Date

Signature of Investigator

Date 


\section{References}

Ainsworth, M. D. S. (1963). The development of infant-mother interaction among the Ganda. In B. M. Foss (Ed.), Determinants of Infant Behavior (Vol. 2, pp. 67-112). New York: Wiley.

Ainsworth, M., (1967). Infancy in Uganda. Johns Hopkins Press, Baltimore.

Ainsworth, M. D. S. (1972) Attachment and dependency: A comparison. In J. L. Gewirtz (Ed,), Attachment and Dependency (pp. 97-137). Washington, DC: V.H. Winston

Ainsworth, M. D. S., Blehar, M., Waters, E., \& Wall, S. (1978). Patterns of Attachment: A Psychological Study of The Strange Situation. Hillsdale, NJ: Erlbaum.

Anderson, K. \& Jack, D. (1991). Learning to Listen: Interview Techniques and Analyses. In B. Gluck and D. Patai (Eds.), Women's Words: The Feminist Practice of History (pp. 1126). New York, NY: Routledge.

Aronson, J . \& S. Sammon. 2000. "Practice Amid Social Service Cuts and Restructuring: Working with the Contradictions of 'Small Victories'", Canadian Social Work Review 17(2), 167-187.

Baines, D. (2007). Introduction-Anti-oppressive social work: Fighting for space, Fighting for Change. In D. Baines (Ed.), Doing Anti-Oppressive Practice: Building Transformative Politicized Social Work (pp. 1-30). Nova Scotia: Fernwood.

Bala, N., Zapf, K. M., Williams, J. R., Vogl, R. \& Hornick, P. J. (2004). Canadian Child Welfare Law: Children, Families and the State. (2nd ed.). Toronto: Thompson Educational Publishing, Inc.

Baskin C. (2003). Structural social work as seen from an Aboriginal Perspective. In W. Shera (Ed.), Emerging Perspectives on Anti-oppressive Practice, pp. 65- 78. Toronto: Canadian Scholar's Press.

Belsky, J., Rovine, M. \& Taylor, G. D., (1984). The Pennsylvania Infant and Family Development Project, III: The Origins of Individual Differences in Infant-Mother Attachment: Maternal and Infant Contributions. Child Development, 55(3), 718-728.

Blackstock, C., Trocme, N. \& Bennett, M. (2004). Child Maltreatment Investigations Among Aboriginal and non-Aboriginal Families in Canada. Violence Against Women, 10(8), 901-916.

Bowlby, J. (1959). Separation anxiety. International Journal of Psycho-Analysts, XLI, 1-25.

Bowlby, J. \& Ainsworth M. (1965) Child Care and the Growth of Love. (2nd ed.). Harmondsworth: Penguin Books.

Bretherton, I. (1992). The Origins of Attachment Theory: John Bowlby and Mary Ainsworth. Developmental Psychology, 28, 759-775.

Brown, L. \& Strega, S. (2005). Transgressive Possibilities. In L. Brown \& S. Strega (Eds.), 
Research as Resistance: Critical, indigenous and anti-oppressive approaches (pp. 1-18). Toronto: Canadian Scholars' Press.

Butler, J. (1993). Bodies That Matter: on The Discursive Limits of 'sex'. London: Routledge.

Carlson, E. (1998). A prospective longitudinal study of attachment disorganization/disorientation. Child Development, 69, 1107-1128.

CASW [include the full name]. (2005). Social Work Code of Ethics. Ottawa: Canadian Association of Social Workers (CASW).

Chase, S. E. (2003). Learning to listen: Narrative in a qualitative research methods course. In R. Josselson, A. Lieblich; D. P. McAdams (Eds.) Up Close and Personal: The Teaching and Learning of Narrative Research (pp.79-99). Washington, DC: American Psychological Association.

Chilisa, B. (2012). Whose Reality Counts? Research Methods in Question. In Indigenous Research Methodologies. Los Angeles: Sage.

Collings, S. \& Davies, L. (2008). For The Sake of Children: Making Sense of Children and Childhood in the Context of Protection. Journal of Social Work Practice, 2(22), 181-193.

Connelly, F. M \& Clandinin, D. J. (2000). Narrative Inquiry: Experience and Story in Qualitative Research. San Francisco, CA: Jossey Bass.

Connelly, F. M \& Clandinin, D. J. (1990). Stories of Experience and Narrative Inquiry. Educational Researcher, 19(5), 2-14.

Das Gupta, T. (1996). Racism and Paid Work. Toronto: Garamond Press.

D’Cruz, H., Gillingham, P. \& Melendez, S. (2007). Reflexivity, Its Meanings and Relevance for Social Work: A critical Review of the Literature. British Journal of Social Work, 37, 7390 .

Dei, G. \& Asgharzadeh (2001). The Power of Social Theory: The Anti-Colonial Discursive Framework. Journal of Educational Thought, 35(3), 297-323.

Dei, S. G., \& Kempf, A. (2006). Australia and France On Fire: An Anti-colonial Critique. International Education, 36(1), 63-82, 96-97.

DeWolff, M. S., \& van Ijzendoom, M. H. (1997). Sensitivity and attachment: A metaanalysis on parental antecedents of infant attachment. Child Development, 68, 571-591.

Durrett, E. M., Otaki, M. \& Rirchards, P., (1984). Attachment and the Mother's Perception of Support From the Father. International Journal of Behavioral Development, 7, 167-176.

Erdman, P. \& Ng, K. (2010). Attachment: Expanding the cultural connections. New York: Routledge.

Finlay, L. (2008) Reflecting on 'Reflective Practice'. Practice-Based Professional Learning Centre, 52, 1-27.

Fook, J. (2002). Social work: Critical theory and practice. London: Sage.

Foucault . M. (1980) Power and Knowledge: New York: Pantheon Books. 
Fraser, H. (2004). Doing narrative research. Qualitative Social Work, 3(2), 179-201.

Gray, M. (2005). Dilemmas of international social work: paradoxical processes in indidgenisation, universalism and imperialism. International Journal of Social Welfare, 14(3), 231-238.

Grossmann, K., Grossmann, E. K., Spangler, Suess \& Unzer, (1985). Maternal Sensitivity and Newborns' Orientation Responses as Related to Quality of Attachment in North Germany. Child Development, 50 (1/2), 233-356.

Hamdan, K. A. (2009). Reflexivity of Discomfort in Insider-Outsider Educational Research. McGill Journal of Education, 44 (3), 377-404.

Hart, M. (2009). Anti-Colonial Indigenous Social Work: Reflections on an Aboriginal Approach. In R. Sinclair, M. Hart and G. Bruyere (Eds.), Wichitowin: Aboriginal Social Work in Canada (pp. 22-41). Nova Scotia: Fernwood Publishing

Healy, K., Darlington, Y., \& Yellowlees, J. (2011). Family participation in child protection practice: An observational study of family group meetings. Child and Family Social Work, 17(1), 1-12.

Heitritter, D. Lynn (1999). Somali Family strength: Working in the communities, Minneapolis, MN: University of Minnesota Extension Service.

Heller, K. A., \& Bemdt, T. J. (1981). Developmental changes in the formation an organization of personality attributions. Child Development, 52, 683-691.

Heron, B. (2005). Self-reflection in Critical Social Work Practice: Subjectivity and the Possibilities of Resistance. Reflective Practice: International and Multidisciplinary Perspectives, 6(3), 341-351.

Howe, D., Brandon, M., Hinings, D. \& Schofield, G. (1999). Attachment Theory, Child Maltreatment and Family Support: A Practice and Assessment Model. England: Palgrave Macmillan.

Humphrey, C. (2007). Insider-Outsider: Activating the Hyphen. Sage Publication, 5(1), 11-26.

Jin, K. M., Jacobvitz, D. \& Hazen, N. (2010). A Cross-Cultural Study of Attachment in Korea and the United States. In P. Erdman \& K. Ng (Eds). Attachment (pp.143-156). New York: Routledge Taylor \& Francis Group.

Kamani, K., Regehr, C. \& Bernstein, M. M. (2002). Liability Considerations in Child Welfare: Lessons from Canada. Child Abuse \& Neglect, 26, 1029-1043.

Keller, H. (2013). Attachment and Culture. Journal of Cross-Cultural Psychology, 44 (2), 175 194.

Keller, H., Voelker, S., Yovsi, D. R. (2005). Conceptions of Parenting in Different Cultural Communities: The Case of West African Nso and Northern German Women. Social Development, 14(1), 158-180. 
Kermoian, R., \& Leiderman, P. H. (1986). Infant attachment to mother and child caretaker in a East African community. International Journal of Behavioral Development, 9, 455-469.

Kincheloe, J. (1999). The Struggle to Define and Reinvent Whiteness: A Pedagological Analysis. College Literature, 24 (1), 162-194.

Kobak, R. (1999). The emotional dynamics o f disruptions in attachment relationships. In J.Cassidy, \& P. R. Shaver (Eds.), Handbook of Attachment: Theory, Research and Clinical Applications (pp. 21-43). New York: Guilford Press.

Lee, E. \& Bhuyan, R. (2013). Negotiating within Whiteness in Cross-Cultural Clinical Encounters. Social Service Review, 87 (1), 98-130.

Madison, S. (2005). Critical Ethnography: Methods, Ethics \& Performance. Thousand Islands, CA: Sage Publications

Mennen, E. F. \& O'Keefe, M. (2005). Informed Decisions in Child Welfare: The use of Attachment Theory. Children and Youth Services Review, 27, 577-593.

Mumby, D., \& Clair, R. P. (1997). Organizational Discourse. In T.A. van Dijk (Ed.), Discourse as Social Interaction. Discourse Studies. Multidisciplinary Introduction (pp. 1, 181-205). London: Sage Publishing.

Mungwini, P. (2012). Surveillance and Cultural Panopticism: Situating Foucault in African Modernities. South African Journal of Philosophy, 31 (2), 340-353.

Neckoway, R, Brownlee \& Castellan, B. (2007).Is Attachment Theory Consistent with Aboriginal Parenting Realties. Journal of Innovation and Best Practices in Aboriginal Child Welfare Administration, 3(2), 65-74.

Neuman, W. L. (2006) Social Research Methods: Qualitative and Quantitative approaches. $6^{\text {th }}$ ed.). Toronto: Pearson.

Ontario Association of Children's Aid Societies. (2012). Child Welfare Report 2012. Toronto: OACAS.

Ontario Association of Children's Aid Societies. (2010). Child Welfare. Toronto: OACAS.

Ontario Child Welfare Secretariat. (2006). Ontario Child Protection Tools Manual. Toronto: Ministry of Children and Youth Services.

Peile, C. and McCouat, M. (1997). The risk of relativism: the future of theory and knowledge development in social work. British Journal of Social Work, 27, 343-360.

Pon G., Gosine, K. \& Phillips. D. (2011). Immediate Response: Addressing Anti-Native andAnti-Black Racism in Child Welfare. International Journal of Child, Youth and Family Studies, 3\&4, 385-409.

Pon, G. (2009). Cultural competency as new racism: An ontology of forgetting.Journal of Progressive Human Services, 20(1), 59-71.

Potts, K. \& Brown, L. (2005), Becoming an anti-oppressive researcher. In L. Brown \& S. 
Strega (Eds.), Research as Resistance: Critical Indigenous \& Anti-Oppressive Approaches (pp. 255-286). Toronto: Canadian Scholars' Press.

Powell, L. J. (2012). Social Work, Power and Performativity. China Journal of Social Work, 5 (1), 67-79.

Quijano, A. (2000). Coloniality of Power, Eurocentrism, and Latin America. Nepantla: Views from South, 1(3), 533-580.

Rabinow, P. (1991) The Foulcault Reader: An introduction to Foulcault's Thought. London: Penguin.

Razack, S. H. (2002). Race, Space and the Law: Unmapping of a White Settler Society. Toronto: Between the Lines.

Reich, J. (2005). Fixing Families: parents, power and the child welfare system. New York: Routledge.

Rossiter, A. (2005). Discourse Analysis in Critical Social Work: From Apology to Question. Critical Social Work, 6(1), 1-8.

Rothbaum, F., Weiz, J., Pott, M., Miyake, K. \& Morelli, G. (2000). Attachment and Culture: Security in the United States and Japan. American Psychological Association, 55 (10), 1093-1104.

Rutter, M., \& O’Connor, T. G. (1999). Implications of attachment theory for child care policies. In J. Cassidy, \& P. R. Shaver (Eds.), Handbook of Attachment: Theory, Research and ClinicalApplications (pp. 823-844). New York: Guilford Press.

Schmid, J. (2009). Subjectivities in South African Child Welfare Discourse. Transformation: Critical Perspectives on Southern Africa, 70, 92-118.

Schwandt, T. A. (2007). The Sage Dictionary of Qualitative Inquiry (3rd Ed.). Thousand Oaks, CA: Sage Publications.

Sinclair, R. (2004). Aboriginal Social Work Education in Canada: Decolonizing Pedagogy for the Seventh Generation. First Peoples Child \& Family Review, 1(1), 49-61.

Squire, C. (2008). Experience-Centered and Culturally-Oriented Approaches to Narrative. In M. Andrews, C. Squire \& M. Tamboukou (Eds.), Doing Narrative Research (pp. 41-63). London, England: Sage Publications.

Steinhauer, D. P. (1983). Assessing for Parenting Capacity. The American Journal of Orthopsychiatry, 53 (3), 468-481.

Strega, S. (2009). Anti-Oppressive Approaches to Assessments, Risk Assessments and File Recording. In S. Strega \& J. Carriere (Eds.), Walking This Path Together; Anti-Racist and Anti-Oppressive Child Welfare Practice (pp. 142-154). Winnipeg: Frenwood Publishing.

Strega, S. (2005). The view from the post-structural margins: Epistemology and methodology reconsidered, In L. Brown \& S. Strega (Eds.), Research as Resistance (pp. 199-236). Toronto: Canadian Scholars' Press. 
Strega, S. (2007). Anti-Oppressive Practice in Child Welfare. In D. Baines (Eds.), Doing AntiOppressive Practice: Building Transformative Politicized Social Work (pp. 67-82). Nova Scotia: Fernwood Publishing.

Sümer, N. \& Kağitçibaşi, Ç. (2010), Culturally Relevant Parenting Predictors of Attachment Security Perspectives From Turkey. In P. Erdman \& K. Ng (Eds.), Attachment (pp. 157180). New York: Routledge Taylor \& Francis Group.

Takahashi, K. (1990). Are the Key Assumptions of the 'Strange Situation' Procedure Universal? A View from Japanese Research. Human Development, 33, 23-30.

Taylor, C. (2004). Underpinning Knowledge for Child Care Practice: Reconsidering Child Development Theory. Child and Family Social Work, 9, 225-235.

Taylor, C. (2006). Narrating Significant Experience: Reflective Accounts and the Production of (Self) Knowledge. British Journal of Social Works, 36, 189-206.

Tomlinson M., Cooper, P. \& Murray, L. (2005). The Mother-Infant Relationship and Infant Attachment in a South African Peri-Urban Settlement, Child Development, 76 (5), 10441054

True, M. M., Pisani, L. \& Oumar, F., (2001). Infant-Mother Attachment among The Dogon of Mali. Child Development, 72 (5), 1451-1466.

Van Dijk, T. (1993). Principles of Critical Discourse Analysis. Sage Social Science Collections, 4(2), 249-283.

Weinfeld, N. S., Sroufe, L. A., Egeland, B., \& Carlson, E.A. (1999). The nature of individual differences in infant-caregiver attachment. In J. Cassidy, \& P. R. Shaver (Eds.), Handbook of Attachment: Theory, Research and Clinical Applications (pp. 68-88). New York: Guilford Press.

White, M. \& Epston, D. (1990). Narrative Means to the Therapeutic Ends. New York, NY: W.W. Norton \& Company.

Wilkins, D. (2012). Disorganized Attachment Indicates Child Maltreatment: How Is This LinkUseful for Child Protection Social Workers? Journal of Social Work Practice, 26(1), 15-30.

Woodak, R. (1996). Disorders of Discourse. London: Longman Press.

Yee, J. \& Dumbrill, G. (2003). Whiteout: Looking for race in Canadian Social Work Practice. In A. Al-Krenawi \& J. Graham (eds) Multicultural Social Work in Canada: Working with Diverse Ethno-Racial Communities (pp. 98-121). Ontario: Oxford University Press.

Yeo, S.S. (2003). Bonding and Attachment of Australian Aboriginal Children. Child Abuse Review, 12, 292-304. 